\title{
Assessment of therapeutic nutritional knowledge of Jordanian nurses
}

\author{
Naseem M. Al-Shwaiyat ${ }^{1, ~ *, ~ A r e e j ~ B . ~ S i n j i l l a w i ~}{ }^{2}$, Abdallah S. Al-Rethaiaa ${ }^{3}$, Alaa-Eldin A. Fahmy ${ }^{3}$, \\ Riyad M. Al-Saraireh², Mohammad M. Aqel², Sabal M. Al-Hajjaj', \\ Alaa S. Al-Sbou ${ }^{2}$ \\ ${ }^{1}$ Department of Clinical Nutrition, College of Applied Health Sciences in Arrass, Qassim University, Saudi Arabia \\ ${ }^{2}$ Division of Nutrition, King Hussein Medical Center, Jordanian Royal Medical Services, Amman, Jordan \\ ${ }^{3}$ College of Applied Health Sciences in Arrass, Qassim University, Saudi Arabia
}

\section{Email address:}

sh_naseem@yahoo.com(N. M. Al-Shwaiyat)

\section{To cite this article:}

Naseem M. Al-Shwaiyat, Areej B. Sinjillawi, Abdallah S. Al-Rethaiaa, Alaa-Eldin A. Fahmy, Riyad M. Al-Saraireh, Mohammad M. Aqel, Sabal M. Al-Hajjaj and Alaa S. Al-Sbou. Assessment of Therapeutic Nutritional Knowledge of Jordanian Nurses. International Journal of Nutrition and Food Sciences. Vol. 2, No. 3, 2013, pp. 142-148. doi: 10.11648/j.ijnfs.20130203.18

\begin{abstract}
Nurses have a great contact with hospitalized patients and play an important role in their nutritional management. The current research is a cross-sectional survey, carried out in Al-Hussein Hospital, King Hussein Medical Center, Amman, Jordan, to study the level of therapeutic nutritional knowledge of Jordanian nurses. Two hundred and fifty registered nurses were invited to participate in this study; all of them were Jordanian of the Arabian ethnicity and were selected by simple random sampling method. Of those, two hundred nurses agreed to participate giving a response rate $80 \%$. Data were collected by self-reported questionnaire of 31-items which its validity and reliability were established. We found that the mean correct-response rate for therapeutic nutritional knowledge of Jordanian nurses was suboptimal (58.8\%). Moreover, the therapeutic nutritional knowledge related to diabetes $(71.6 \%)$ was relatively higher than those related to obesity (59.0\%) and cardiovascular diseases (54.9\%). Woman nurses scored significantly higher correct-response rate for cardiovascular diseases-related therapeutic nutritional knowledge than men (56.6\% vs. 51.9\%). Twenty out of 31 questions were answered correctly by more than $50 \%$ of the nurses. The findings suggest an urgent need to improve the curricula of undergraduate nursing courses regarding the nutrition issues and to promote postgraduate continuing educational programs concerning therapeutic nutrition.
\end{abstract}

Keywords: Assessment, Therapeutic, Nutritional Knowledge, Nurses, Jordan

\section{Introduction}

The trend to reduce the cost of hospital care reforms the health care providers' responsibilities to be broader in order to minimize the actual number of providers working with each client[1]. The dietitian is the nutrition expert in the health care team. However, dietitian is not available all the time to answer the patient's dietary enquiries[2]. Moreover, hospitalized patients are usually less motivated to follow nutritional advices. Their ability to learn about the proper diet may be affected by pain, anxiety or medications[3]. Nurses play an important role in nutrition management for their patients. They have the greatest contact with patients and are often available as a nutritional education resource in the absence of the dietitian[4]. Therefore, nurses are in an ideal position to provide nutritional knowledge and sustain the patient's motivation[5]. Although nurses are not supposed to take the position of the dietitian when patients are at high risk for nutritional problems, they are expected to be aware about the principles of nutrition which enable them to deal with patients at low or mild risk for nutritional problems[2].

Several studies were conducted to investigate the level of nutritional knowledge of nurses in different countries. Suboptimal levels of nutritional knowledge for nurses were reported in Korea and Australia[6-7]. However, higher levels of nutritional knowledge were reported for nurses in the United States and Scotland[8-10]. In contrast, low level of nutritional knowledge was reported for nurses in South Africa[11]. In our literature search, we did not find any report regarding the level of nutritional knowledge of Jordanian nurses. The current work was conducted to study 
the level of nutritional knowledge of Jordanian nurses. Keeping in mind that the Jordanian health sectors do not provide nursing staff with continuing educational programs about therapeutic nutrition, we expect to find a low level of nutritional knowledge among Jordanian nurses.

\section{Methods}

\subsection{Design and Participants}

The study is a cross-sectional survey, conducted during January, 2011 in Al-Hussein Hospital, King Hussein Medical Center, Amman, Jordan which is the largest multidisciplinary medical institution in Jordan. Two hundred and fifty registered nurses were invited to participate in this study; all of them are Jordanian of the Arabian ethnicity and were selected by simple random sampling method. Of those, two hundred nurses agreed to participate according to Helsinki Declaration giving $80 \%$ response rate. The study protocol was approved by the committee of human research ethics in the Jordanian Royal Medical Services.

\subsection{Questionnaire}

A self-reported questionnaire was designed to study the therapeutic nutritional knowledge of nurses. It was adopted from items used in previous studies[6-8]. Data were collected using the Arabic version of an adopted questionnaire. Translation and back-translation were carried out by linguistic professionals according to Chen and Boore[12]. The questionnaire was distributed to the participants in their workplace by the researchers. Nurses were informed about the study and were given instructions on how to fill out the questionnaire completely and truthfully.

The questionnaire was structured in two sections. The first section asked about the demographic characteristics (gender, age group, educational level, and years of experience). The second section of the questionnaire included the therapeutic nutritional knowledge questions (31 items). Validity and reliability were established for the instrument. Face validity was assessed using a focus group from the target population to ensure understanding and cultural appropriateness of the questions. The focus group revealed that three items should be modified to reflect cultural differences. Reliability was measured for the 31 items questionnaire and the Cronbach's alpha coefficient value was 0.709 . The questionnaire asked about nutritional knowledge related to diabetes (5 items), obesity (9 items) and cardiovascular diseases (17 items). Sixteen items had 3 choices to answer from, while the remaining 15 questions had 6 choices. Bias caused by guessing was minimized by including a "don't know" category in each question's choices. The correct-response for each question was scored as (1), while incorrect and "don't know" answers were given (0). Thus, the total score was 31 points distributed as 5, 9 and 17 for diabetes, obesity and cardiovascular diseases respectively. These scores were used to calculate the correct-response rate for therapeutic nutritional knowledge of nurses.

\subsection{Data Analysis}

The demographic characteristics of the participants and their response for each question choices were assessed and expressed as numbers and percentages. The correct-response rates for the therapeutic nutritional knowledge were assessed and expressed as means and standard deviations. Comparison for means of correct-response rates was performed using Student's $t$-test. Differences were considered statistically significant at $p$ value $<0.05$. The Statistical Package for Social Sciences (SPSS version 17, Inc., Chicago, IL, USA) was used for data analysis.

\section{Results}

\subsection{Nurses' Characteristics}

Two hundred nurses participated in the current study; 37\% of them were men (Table 1). Those with an Associate degree formed $26 \%$, while the remaining had a Bachelor's degree. About half of the participants (49\%) aged 20-25 years, while $51 \%$ aged 26 years or more. Finally, nurses with $1-5$ years of experience represented $64.5 \%$ of the studied sample, while the remaining had 6 years of experience or more.

\subsection{Therapeutic Nutritional Knowledge}

Results showed that the mean correct-response rate for therapeutic nutritional knowledge of Jordanian nurses was $58.8 \%$ (Table 1). Moreover, the therapeutic nutritional knowledge related to diabetes $(71.6 \%)$ was relatively higher than those related to obesity $(59.0 \%)$ and cardiovascular diseases $(54.9 \%)$. Woman nurses scored significantly higher correct-response rate for therapeutic nutritional knowledge related to cardiovascular diseases than men $(56.6 \%$ vs. $51.9 \%$ ).

Twenty out of 31 questions were answered correctly by more than $50 \%$ of the nurses. Ten of these questions were answered correctly by more than $75 \%$ of the sample (Tables 2, 3 and 4). The highest correct-response rate was obtained when $91 \%$ of nurses agreed with the recommendation of a high fiber diet for obesity. In contrast, the lowest correct-response rate was recorded when only $10 \%$ of nurses chose that decreasing total fat intake as a first recommended diet therapy for obese 45 year-old adult with blood cholesterol level of $239 \mathrm{mg} / \mathrm{dl}$. About $70 \%$ of nurses knew that diabetic patients can eat fruits and should restrict animal fat and carbohydrates intake. Interestingly, only $38 \%$ of nurses knew that high fat intake is more responsible for obesity than high sugar intake. On the other hand, the majority of the participants agreed with the importance of reducing carbohydrate $(88.5 \%)$ and animal fat (74\%) to lose body weight. Most of the nurses linked between hypertension and obesity (90\%), and recommended low sodium diet for hypertensive patients (84\%). High percentages of participants believed that cardiovascular diseases' patients should limit their intake of saturated fat $(87 \%)$, trans fat $(50 \%)$, and caffeinated beverages $(88 \%)$. 
Although $69 \%$ of nurses agreed that high blood cholesterol correctly the maximum level of dietary cholesterol increases the incidence of heart disease, only $12.5 \%$ selected

recommended in low-cholesterol diet.

Table 1. The demographic characteristics of nurses and their correct-response rates for therapeutic nutritional knowledge

\begin{tabular}{|c|c|c|c|c|c|}
\hline Variables & Nurses N (\%) & Diabetes Mean (SD) & Obesity Mean (SD) & $\begin{array}{c}\text { Cardiovascular diseases } \\
\text { Mean (SD) }\end{array}$ & Total Mean (SD) \\
\hline All Participants & $200(100 \%)$ & $71.6(24.3)$ & $59.0(16.7)$ & $54.9(15.5)$ & $58.8(13.2)$ \\
\hline \multicolumn{6}{|l|}{ Gender } \\
\hline Men & $74(37 \%)$ & $72.2(25.4)$ & $56.8(18.1)$ & $51.9(17.5)$ & $56.6(14.5)$ \\
\hline Women & $126(63 \%)$ & $71.3(23.7)$ & $60.3(15.7)$ & $56.6(14.0)$ & $60.0(12.3)$ \\
\hline$p$ value & & 0.802 & 0.146 & $0.04 *$ & 0.074 \\
\hline \multicolumn{6}{|l|}{ Age Group } \\
\hline $20-25$ years & $98(49 \%)$ & $71.8(21.5)$ & $59.6(15.6)$ & $55.0(14.6)$ & $59.1(11.9)$ \\
\hline$\geq 26$ years & $102(51 \%)$ & $71.4(26.8)$ & $58.4(17.7)$ & $54.7(16.4)$ & $58.4(14.4)$ \\
\hline$p$ value & & 0.893 & 0.598 & 0.867 & 0.733 \\
\hline \multicolumn{6}{|l|}{ Education Level } \\
\hline Associate degree & $52(26 \%)$ & $69.6(24.3)$ & $58.1(16.4)$ & $55.8(14.2)$ & $58.7(12.3)$ \\
\hline Bachelor's degree & $148(74 \%)$ & $72.3(24.3)$ & $59.3(16.8)$ & $54.5(16.0)$ & $58.8(13.2)$ \\
\hline$p$ value & & 0.494 & 0.659 & 0.622 & 0.963 \\
\hline \multicolumn{6}{|l|}{ Years of Experience } \\
\hline $1-5$ years & $129(64.5 \%)$ & $71.3(24.2)$ & $58.7(17.7)$ & $54.4(16.4)$ & $58.3(14.1)$ \\
\hline$\geq 6$ years & $71(35.5 \%)$ & $72.1(24.5)$ & $59.6(14.7)$ & $55.8(14.0)$ & $59.5(11.5)$ \\
\hline$p$ value & & 0.825 & 0.696 & 0.543 & 0.548 \\
\hline
\end{tabular}

* Means are significantly different at $p$ value $<0.05$ by Student's $t$-test.

Table 2. Nurses' response for diabetes-related therapeutic nutritional knowledge questions

\begin{tabular}{|c|c|c|c|}
\hline \multirow{2}{*}{ Questions Asked } & \multirow{2}{*}{ Answer Levels } & \multicolumn{2}{|c|}{ Nurses' Response } \\
\hline & & $\mathbf{N}$ & $\%$ \\
\hline \multirow{3}{*}{$\begin{array}{l}\text { 1. Fruits should not be consumed by the diabetic } \\
\text { patients. }\end{array}$} & A. Agree & 54 & 27 \\
\hline & B. Disagree* & 143 & 71.5 \\
\hline & C. Don't know & 3 & 1.5 \\
\hline \multirow{3}{*}{$\begin{array}{l}\text { 2. Only carbohydrates have to be restricted for the } \\
\text { diabetic patients. }\end{array}$} & A. Agree & 44 & 22 \\
\hline & B. Disagree* & 140 & 70 \\
\hline & C. Don't know & 16 & 8 \\
\hline \multirow{3}{*}{ 3. Animal fat should be restricted for diabetic patients. } & A. Agree* & 137 & 68.5 \\
\hline & B. Disagree & 51 & 25.5 \\
\hline & C. Don't know & 12 & 6 \\
\hline \multirow{6}{*}{$\begin{array}{l}\text { 4. The product which should not be used for patients } \\
\text { with hypoglycemia is: }\end{array}$} & A. Candy & 11 & 5.5 \\
\hline & B. Orange juice & 4 & 2 \\
\hline & C. Sugar-free carbonated beverages* & 141 & 70.5 \\
\hline & D. Skim milk & 17 & 8.5 \\
\hline & E. Chocolate & 7 & 3.5 \\
\hline & F. Don't know & 20 & 10 \\
\hline \multirow{6}{*}{ 5. What is the recommended diet for diabetic patients? } & A. Standard American diet & 6 & 3 \\
\hline & B. Balanced diet* & 155 & 77.5 \\
\hline & C. A high carbohydrate diet & 3 & 1.5 \\
\hline & D. A high fat diet & 4 & 2 \\
\hline & E. A high protein diet & 25 & 12.5 \\
\hline & F. Don't know & 7 & 3.5 \\
\hline
\end{tabular}

* The correct answer.

Table 3. Nurses'response for obesity-related therapeutic nutritional knowledge questions

\begin{tabular}{|c|c|c|c|}
\hline Questions Asked & Answer Levels & $\begin{array}{c}\text { Nurse } \\
\mathbf{N}\end{array}$ & $\%$ \\
\hline \multirow{4}{*}{$\begin{array}{l}\text { 1. High sugar intake is more responsible for causing } \\
\text { obesity than high fat intake. }\end{array}$} & A. Agree & 115 & 57.5 \\
\hline & B. Disagree* & 76 & 38 \\
\hline & C. Don't know & 9 & 4.5 \\
\hline & A. Agree* & 182 & 91 \\
\hline \multirow[t]{2}{*}{ 2. A high fiber diet is recommended for obesity. } & B. Disagree & 13 & 6.5 \\
\hline & C. Don't know & 5 & 2.5 \\
\hline \multirow{3}{*}{$\begin{array}{l}\text { 3. Carbohydrate intake should be reduced to lose body } \\
\text { weight. }\end{array}$} & A. Agree* & 177 & 88.5 \\
\hline & B. Disagree & 19 & 9.5 \\
\hline & C. Don't know & 4 & 2 \\
\hline
\end{tabular}




\begin{tabular}{|c|c|c|c|}
\hline \multirow{3}{*}{$\begin{array}{l}\text { 4. Animal fat should be removed from meal to lose } \\
\text { body weight. }\end{array}$} & A. Agree* & 148 & 74 \\
\hline & B. Disagree & 41 & 20.5 \\
\hline & C. Don't know & 11 & 5.5 \\
\hline \multirow{4}{*}{$\begin{array}{l}\text { 5. Android (upper body) obesity has more } \\
\text { complications such as hypertension and diabetes than } \\
\text { gynoid (lower body) obesity. }\end{array}$} & A. Agree* & 145 & 72.5 \\
\hline & B. Disagree & 23 & 11.5 \\
\hline & C. Don't know & 32 & 16 \\
\hline & A. Decrease monounsaturated fat intake & 18 & 9 \\
\hline \multirow{5}{*}{$\begin{array}{l}\text { 6. An obese } 45 \text { year-old adult has blood cholesterol } \\
\text { level of } 239 \mathrm{mg} / \mathrm{dl} \text {. Which of the following dietary } \\
\text { therapy is the first recommended? }\end{array}$} & B. Decrease polyunsaturated fat intake & 45 & 22.5 \\
\hline & C. Decrease total fat intake* & 20 & 10 \\
\hline & D. Decrease total cholesterol intake & 46 & 23 \\
\hline & E. Decrease carbohydrate intake & 1 & 0.5 \\
\hline & F. Don't know & 70 & 35 \\
\hline \multirow{6}{*}{ 7. Which disorder is not related to the android obesity? } & A. Diabetes & 19 & 9.5 \\
\hline & B. Hyperlipidemia & 16 & 8 \\
\hline & C. Hypertension & 10 & 5 \\
\hline & D. Kidney failure* & 83 & 41.5 \\
\hline & E. Myocardial infraction & 24 & 12 \\
\hline & F. Don’t know & 48 & 24 \\
\hline \multirow{6}{*}{$\begin{array}{l}\text { 8. The food which contains the highest amount of } \\
\text { carbohydrate is: }\end{array}$} & A. Chicken & 6 & 3 \\
\hline & B. Cheese & 3 & 1.5 \\
\hline & C. Potato* & 161 & 80.5 \\
\hline & D. Peanut butter & 12 & 6 \\
\hline & E. Milk & 4 & 2 \\
\hline & F. Don’t know & 14 & 7 \\
\hline \multirow{6}{*}{$\begin{array}{l}\text { 9. The food which contains the highest amount of fat } \\
\text { is: }\end{array}$} & A. Low fat milk* & 70 & 35 \\
\hline & B. Orange juice & 6 & 3 \\
\hline & C. Corn & 30 & 15 \\
\hline & D. Honey & 4 & 2 \\
\hline & E. Soy sauce & 74 & 37 \\
\hline & F. Don't know & 16 & 8 \\
\hline
\end{tabular}

* The correct answer.

Table 4. Nurses' response for cardiovascular diseases-related therapeutic nutritional knowledge questions

\begin{tabular}{|c|c|c|c|}
\hline Questions Asked & Answer Levels & $\begin{array}{c}\text { Nurses } \\
\mathbf{N}\end{array}$ & $\%$ \\
\hline \multirow{3}{*}{$\begin{array}{l}\text { 1. There is a close relationship between hypertension } \\
\text { and obesity. }\end{array}$} & A. Agree* & 180 & 90 \\
\hline & B. Disagree & 16 & 8 \\
\hline & C. Don't know & 4 & 2 \\
\hline \multirow{3}{*}{$\begin{array}{l}\text { 2. For the treatment of hypertension, a low sodium diet } \\
\text { is routinely recommended. }\end{array}$} & A. Agree* & 168 & 84 \\
\hline & B. Disagree & 20 & 10 \\
\hline & C. Don't know & 12 & 6 \\
\hline \multirow{6}{*}{$\begin{array}{l}\text { 3. What kind of mineral is likely to be deficient for the } \\
\text { patients who are on diuretics? }\end{array}$} & A. Sodium & 49 & 24.5 \\
\hline & B. Potassium* & 132 & 66 \\
\hline & C. Calcium & 4 & 2 \\
\hline & D. Magnesium & 1 & 0.5 \\
\hline & E. Iodine & 5 & 2.5 \\
\hline & F. Don't know & 9 & 4.5 \\
\hline \multirow{6}{*}{$\begin{array}{l}\text { 4. The mineral which decreases the risk of } \\
\text { hypertension is: }\end{array}$} & A. Sodium & 37 & 18.5 \\
\hline & B. Calcium* & 49 & 24.5 \\
\hline & C. Iron & 17 & 8.5 \\
\hline & D. Copper & 4 & 2 \\
\hline & E. Zinc & 27 & 13.5 \\
\hline & F. Don't know & 66 & 33 \\
\hline \multirow{3}{*}{$\begin{array}{l}\text { 5. A lower intake of saturated fat decreases the risk of } \\
\text { coronary artery disease. }\end{array}$} & A. Agree* & 174 & 87 \\
\hline & B. Disagree & 17 & 8.5 \\
\hline & C. Don't know & 9 & 4.5 \\
\hline \multirow{3}{*}{$\begin{array}{l}\text { 6. High blood cholesterol increases the incidence of } \\
\text { heart disease. }\end{array}$} & A. Agree* & 138 & 69 \\
\hline & B. Disagree & 12 & 6 \\
\hline & C. Don't know & 5 & 2.5 \\
\hline \multirow{3}{*}{$\begin{array}{l}\text { 7. The trans fats such as margarine are recommended } \\
\text { for cardiovascular disease. }\end{array}$} & A. Agree & 84 & 42 \\
\hline & B. Disagree* & 100 & 50 \\
\hline & C. Don't know & 16 & 8 \\
\hline \multirow{3}{*}{$\begin{array}{l}\text { 8. Omega- } 3 \text { fatty acids such as fish oil help to reduce } \\
\text { hyperlipidemia. }\end{array}$} & A. Agree* & 156 & 78 \\
\hline & B. Disagree & 19 & 9.5 \\
\hline & C. Don't know & 25 & 12.5 \\
\hline 9. Caffeinated beverages are harmful for myocardial & A. Agree* & 176 & 88 \\
\hline
\end{tabular}




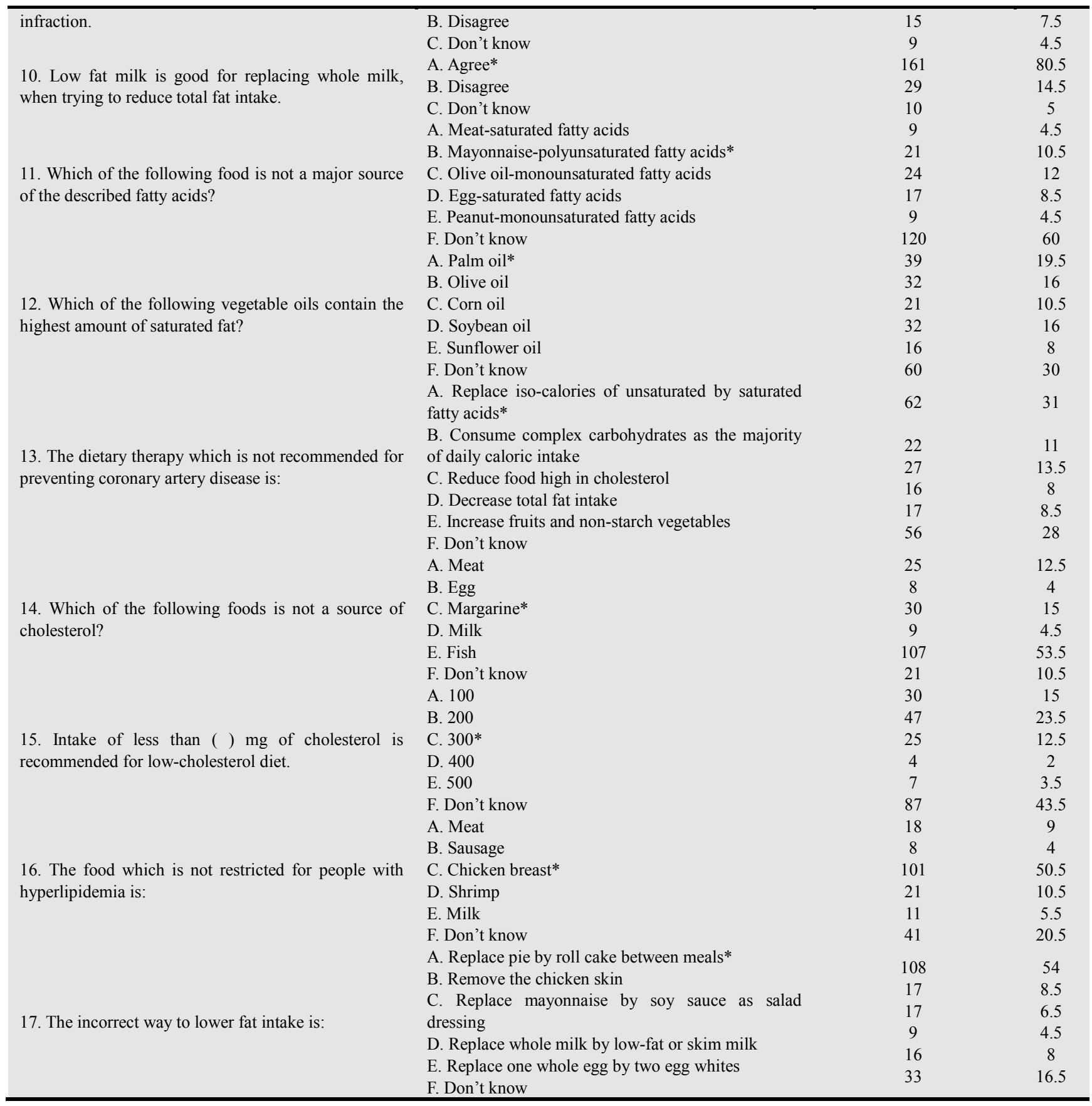

* The correct answer.

\section{Discussion}

Our results revealed that nurses exhibited a suboptimal level of therapeutic nutritional knowledge (mean $=58.8 \%$ ). This finding is consistent with the results of similar studies carried out in Korea and Australia. A 42-items survey conducted by Park et al. showed that the mean nutritional knowledge of 506 Korean nurses was 58.4\%[6]. Similarly, in a 48-items survey conducted among 103 Australian nurses, Schaller and James found that the mean nutritional knowledge was $60.2 \%[7]$. On the other hand, higher levels of nutritional knowledge were reported for nurses in the
United States and Scotland. Warber and colleagues, using a 55 -items survey, found that the mean score of nutritional knowledge among 68 nurse practitioners in New England region was $66 \%[8]$. A similar level of nutritional knowledge (65\%) was reported by Crogan et al. who used a 50 -items survey among 44 nurses working in nursing homes in Washington[9]. Hankey and colleagues evaluated nutritional knowledge and beliefs about obesity of 509 Scottish nurses by asking them 13 questions. They reported the correct-response rate for each question individually; from which we calculated the mean correct response-rate for all questions which was 79.6\%[10]. In contrast, lower levels of nutritional knowledge were reported for nurses in South 
Africa by Kgaphola et al. who carried out a 40-items survey among 99 nurses and found that the mean correct-response rate was $35 \%[11]$. In the current research, Jordanian nurses exhibited a high level of diabetes-related therapeutic nutritional knowledge, and a suboptimal level of their knowledge related to obesity and cardiovascular diseases. Similarly, Park et al. reported higher levels of therapeutic nutritional knowledge related to diabetes $(67.59 \%)$ than those related to obesity $(53.76 \%)$ and cardiovascular diseases $(57.66 \%)$ [6].

Scientific literatures provide a controversial debate about the effect of nurses' demographic characteristics on their nutritional knowledge. In our study, the educational level of nurses had no influence on their nutritional knowledge. Contrarily, a significant direct correlation was documented between the above two parameters by Park et al. and Crogan et al.[6,9]. Surprisingly, this correlation was reported to be significantly inverse by Schaller and James[7]. Our results agreed with those of Crogan et al.[9] that there was no significant correlation between years of experience and nutritional knowledge. On the other hand, Park et al. and Schaller and James revealed that nutritional knowledge elevated significantly with years of experience[6-7]. Age groups and nutritional knowledge showed no significant correlation in the present study. In contrast, Schaller and James found a significant higher nutritional knowledge among older nurses[7].

The American Dietetic Association recommended nutritional education to be an essential component of the curricula for health care professionals[1]. Continuing educational programs regarding nutrition after graduation are in the same level of importance to update nurses' nutritional knowledge[13-14]. Recently, a Danish team investigated the impact of a training program on the nurses' nutritional knowledge and the patients' outcomes of nutritional care. They found that the program enhanced nurses' awareness of nutritional assessment and management. In addition, the patients' knowledge of appropriate food choices from the menu increased; suggesting that the nutritional intake of the patients had improved[15-16]. Nevertheless, most of the Jordanian nursing programs for undergraduate include only one course related to nutrition in health and illness (according to their Websites). Moreover, there are limited continuing educational programs regarding nutrition offered to nurses by public, private or military health sectors in Jordan (according to their Websites).

Nutritional care is considered as an integral part of the primary care provided to hospitalized patients. Therefore, an effective communication and cooperation among professionals involved in the patients' medical care are important for successful nutritional management. Nutritional education at the bedside of patients offered by both dietitian and nurse is more efficient than that done by dietitian alone[2]. Since nurses spend more time with hospitalized patients than other health care professionals, they are able to observe patients' eating patterns, identify potential nutritional problems and provide some dietary advices. When necessary, nurses could request a dietitian's intervention to ensure a comprehensive nutritional management[17].

Finally, the current work was limited by recruiting the participants from only one Jordanian hospital. Participations of nurses from several hospitals across Jordan may provide a more representative study sample. However, being the first attempt, not only in Jordan but also in Middle Eastern countries, to study the level of therapeutic nutritional knowledge of nurses could show the importance of this study.

\section{Conclusions}

The current study was conducted to assess the therapeutic nutritional knowledge of Jordanian nurses. Our results revealed that Jordanian nurses had a suboptimal level of therapeutic nutritional knowledge. This emphasizes the necessity of both improving the curricula of undergraduate nursing courses regarding the nutrition issues and establishing postgraduate continuing educational programs about therapeutic nutrition. The important concern in this area is that nurses that do not have adequate nutritional knowledge are giving advice to their patients that often times is incorrect which is a greater problem. Therefore, educational programs would be helpful in promoting nurses' active involvement in nutritional management for hospitalized patients. We hope that this study constitutes the first step for developing nutritional management practice in Jordanian hospitals.

\section{Acknowledgements}

The authors would like to thank Mr. Moutaz Al-Abdallah for linguistic revision and all nurses who participated in this study. Al-Shwaiyat N., Al-Rethaiaa A. and Fahmy A. designed the research protocol, performed the statistical analysis and wrote the manuscript. Sinjillawi A., Al-Saraireh R., Aqel M., Al-Hajjaj S. and Al-Sbou A. collected the raw data and contributed to the manuscript. Al-Shwaiyat N. supervised all steps of this study.

\section{References}

[1] American Dietetic Association (1998) Position of The American Dietetic Association: Nutrition education for health care professionals. Journal of the American Dietetic Association, 98(3): 343-346.

[2] Dudek, S.G. (2010) Nutrition Essentials for Nursing Practice, 6th edition, Lippincott Williams \& Wilkins, Philadelphia, PA.

[3] Kowanko, I. (1997) The role of the nurse in food service: A literature review and recommendations. International Journal of Nursing Practice, 3(2): 73-78. 
[4] Hopper, D. and Barker, M.E. (1995) Dietary advice, nutritional knowledge and attitudes towards nutrition in primary health care. Journal of Human Nutrition and Dietetics, 8(4): 279-286.

[5] Nowak, M., Harrison, S. \& Hutton, L. (2007) Nutrition-related knowledge, beliefs and practices of Australian nursing staff. Nutrition \& Dietetics, 64(2): $121-126$.

[6] Park, K.A., Cho, W.I., Song, K.J., Lee, Y.S., Sung, I.S. and Choi-Kwon, S.M. (2011) Assessment of nurses' nutritional knowledge regarding therapeutic diet regimens. Nurse Education Today, 31(2): 192-197.

[7] Schaller, C. and James, E.L. (2005) The nutritional knowledge of Australian nurses. Nurse Education Today, 25(5): 405-412.

[8] Warber, J.I., Warber, J.P. and Simone, K.A. (2000) Assessment of general nutrition knowledge of nurse practitioners in New England. Journal of the American Dietetic Association, 100(3): 368-370.

[9] Crogan, N.L., Shultz, J.A. and Massey, L.K. (2001), "Nutrition Knowledge of Nurses in Long-Term Care Facilities", The Journal of Continuing Education in Nursing, 32(4): 171-176.

[10] Hankey, C.R., Eley, S., Leslie, W.S., Hunter, C.M. and Lean, M.E.J. (2004) Eating habits, beliefs, attitudes and knowledge among health professionals regarding the links between obesity, nutrition and health. Public Health Nutrition, 7(2): 337-343.
[11] Kgaphola, M.S., Wodarski, L.A. and Garrison, M.E.B. (1997) Nutrition knowledge of clinic nurses in Lebowa, South Africa: implications for nutrition services delivery. Journal of Human Nutrition and Dietetics, 10(5): 295-303.

[12] Chen, H.Y. and Boore, J.R.P. (2010) Translation and back-translation in qualitative nursing research: methodological review. Journal of Clinical Nursing, 19(1-2): 234-239.

[13] Cadman, L. and Wiles, R. (1996) Nutrition advice in primary care: evaluation of practice nurse nutrition training programmes. Journal of Human Nutrition and Dietetics, 9(2): $147-156$

[14] Kennelly, S., Kennedy, N.P., Rughoobur, G.F., Slattery, C.G. and Sugrue S. (2010) An evaluation of a community dietetics intervention on the management of malnutrition for healthcare professionals. Journal of Human Nutrition and Dietetics, 23 (6): 567-574.

[15] Bjerrum, M., Tewes, M. and Pedersen, P. (2012) Nurses' self-reported knowledge about and attitude to nutrition before and after a training programme. Scandinavian Journal of Caring Sciences, 26 (1): 81-89.

[16] Pedersen, P.U., Tewes, M. and Bjerrum, M. (2012) Implementing nutritional guidelines - the effect of systematic training for nurse nutrition practitioners. Scandinavian Journal of Caring Sciences, 26 (1): 178-185.

[17] Kim, H. and Choue, R. (2009) Nurses' positive attitudes to nutritional management but limited knowledge of nutritional assessment in Korea. International Nursing Review, 56(3): 333-339. 